\title{
Independent spatial patterns: an integration of common spatial patterns with independent component analysis for multi- class discrimination in EEG based brain-computer interfaces
}

\author{
Muhammad Naeem*, David Watson, Girijesh Parasad
}

From Nineteenth Annual Computational Neuroscience Meeting: CNS*2010

San Antonio, TX, USA. 24-30 July 2010

Independent spatial patterns (ISP) aims to integrate common spatial patterns (CSP) and Independent component analysis (ICA) by utilizing the best features of the two methods and at the same time going round some of the caveats associated with them. In the case of ICA importance of components cannot be pre-determined. Principal component analysis (PCA) dimensional reduction does not provide reasonable estimate [1]. A visual selection of ICA components [2] still performed sub-optimally. On the other hand, multi-class implementation of CSP is also plagued with number of issues. It works on heuristics by employing one-vs-rest scheme [3]. The resultant 4 projection matrices (in the case of 4-class problem) creates identification problem: there is no way to determine whether the observed differences in conditions are due to multiple projection matrices or distinct brain activity. No wonder, low detection rate is usually observed for unseen data.

Based on the physiological considerations left and right hand movement can be envisioned as (-vely) correlated tasks. That is, a trial associated with left imagination would typically depict de-synchronization over contra-lateral region (around C4) followed by synchronization over ipsi-lateral region (around C3). Almost diametrically reverse phenomenon is observed in the case of right movement imagination. Same line of argument is valid for foot and tongue movement imaginations [4]. Therefore, one pair of correlated signals was separated from the other pair into distinct clusters- each containing only 4 components - by employing CSP. On account

\footnotetext{
* Correspondence: m.naeem@ulster.ac.uk

Intelligent Systems Research Centre, University of Ulster, Londonderry BT487JL, Northern Ireland, UK
}

of CSP criterion of maximization of kurtosis by Eigen value decomposition [5], these clusters are nothing but orthogonal independent components. However, orthogonality with respect to independence criterion is an unnecessary constraint. Therefore, the basis was further rotated by employing infomax principle [6] to achieve maximal independence. Experimental paradigm and details of feature extraction and classification scheme can be found in [2]. Succinctly, analysis was performed on 4 class motor imagery data sets consisted of 8 subjects and two sessions. Spatial filters and classifiers were built on the first session and employed on second session. For estimating ICA and ISP data sets were pre-filtered with same settings. Evaluation and estimation of CSP is detailed in [2].

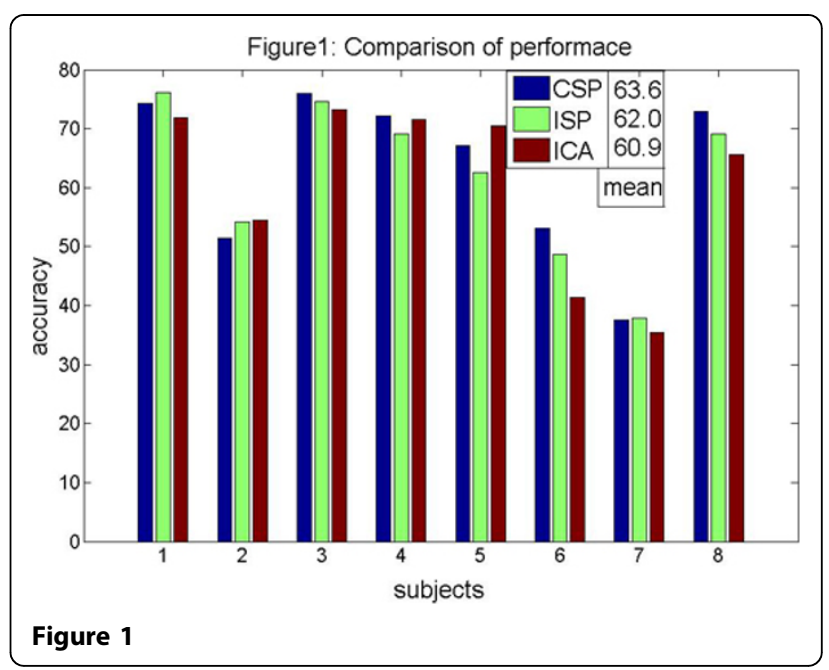


It should be noted that ISP has only one projection matrix and utilized 8 components which was significantly less than (full) 22 components of ICA and 24 CSP projections. The performance of ISP was found to be marginally better than ICA and slightly worse in comparison with CSP (see Figure 1). However, ISP has the potential of improving further its overall performance by the optimization of infomax. This can be achieved by incorporating prior information available in the form of distinct clusters as constraint in infomax cost function. Therefore, ICA decomposition can be performed by minimizing the information between clusters while at the same time maximizing information of individual components of each cluster. The work in this direction is in progress.

Published: 20 July 2010

\section{References}

1. Naeem M, Brunner C, Pfurtscheller G: Dimensional reduction and channel selection of motor imagery EEG data. Comput Intell Neurosci 2009,

2. Naeem M, Brunner C, Leeb R, Graimann B, Pfurtscheller G: Separability of four-class motor imagery data using independent components analysis. JNE 2006, 3:208-216.

3. Grosse-Wentrup M, Buss M: Multiclass Common Spatial Patterns and Information Theoretic Feature Extraction. IEEE Trans. Biomed. Eng 2008, 55(8)

4. Pfurtscheller G, Brunner C, Schloegl A, Lopes DaSilva FH: Mu rhythm (de) synchronization and EEG single-trial classification of different motor imagery tasks. Neuroimage 2006, 31:153-9.

5. Parra LC, Spence CD, Gerson AD, Sajda P: Recipes for the linear analysis of EEG. Neurolmage 2005, 28:326-341.

6. Bell AJ, Sejnowski TJ: An information-maximization Approach to blind separation and blind de-convolution. Neural. Comput. 1995, 7:1129-59.

doi:10.1186/1471-2202-11-S1-P88

Cite this article as: Naeem et al:: Independent spatial patterns: an integration of common spatial patterns with independent component analysis for multi- class discrimination in EEG based brain-computer interfaces. BMC Neuroscience 2010 11(Suppl 1):P88.

\section{Submit your next manuscript to BioMed Central} and take full advantage of:

- Convenient online submission

- Thorough peer review

- No space constraints or color figure charges

- Immediate publication on acceptance

- Inclusion in PubMed, CAS, Scopus and Google Scholar

- Research which is freely available for redistribution

Submit your manuscript at www.biomedcentral.com/submit 